OPEN ACCESS

Edited by:

Wei-Hua Yan,

Wenzhou Medical University, China

Reviewed by:

Christophe Picard,

Établissement Français du Sang

(EFS), France

Reem Al-Daccak

Institut National de la Santé et de la

Recherche Médicale (INSERM),

France

${ }^{*}$ Correspondence:

Francesco Puppo

puppof@unige.it

Specialty section:

This article was submitted to Alloimmunity and Transplantation,

a section of the journal

Frontiers in Immunology

Received: 15 March 2020

Accepted: 17 June 2020

Published: 28 August 2020

Citation:

Contini P, Murdaca G, Puppo F

and Negrini S (2020) HLA-G

Expressing Immune Cells in Immune

Mediated Diseases.

Front. Immunol. 11:1613.

doi: 10.3389/fimmu.2020.01613

\section{HLA-G Expressing Immune Cells in Immune Mediated Diseases}

\author{
P. Contini, Giuseppe Murdaca, Francesco Puppo* and Simone Negrini \\ Department of Internal Medicine, University of Genoa, Genoa, Italy
}

$H L A-G$ is a HLA class $\mathrm{lb}$ antigen that possesses immunomodulatory properties. HLAG-expressing CD4+ and CD8+ T lymphocytes, NK cells, monocytes, and dendritic cells with immunoregulatory functions are present in small percentages of patients with physiologic conditions. Quantitative and qualitative derangements of $\mathrm{HLA}-\mathrm{G}+$ immune cells have been detected in several conditions in which the immune system plays an important role, such as infectious, neoplastic, and autoimmune diseases as well as in complications from transplants and pregnancy. These observations strongly support the hypothesis that HLA-G+ immune cells may be implicated in the complex mechanisms underlying the pathogenesis of these disorders.

Keywords: HLA-G, immune mediated diseases, lymphocytes, dendritic cells, monocytes, NK cells, regulatory cells

\section{INTRODUCTION}

HLA-G is a HLA class Ib antigen characterized by a restricted tissue expression, low polymorphism and seven isoforms (HLA-G1 to HLA-G7) $(1,2)$. In both membrane-bound and soluble form, HLA$\mathrm{G}$ exerts several immune-modulatory effects. It inhibits allogeneic proliferation of CD4+ T cells (3), natural killer (NK) and CD8 + T cells cytotoxicity (4), maturation of dendritic cells (DC) (5), and activation of B cells (6). In addition, soluble HLA-G molecules (sHLA-G) are able to trigger apoptosis in antigen specific CD8+ T lymphocytes $(4,7,8)$.

HLA-G also seems to be involved in the tuning of immune responses. The incubation of peripheral blood mononuclear cells (PBMC) with HLA-G-expressing cells, favors a shift toward a Th-2 cytokine profile; whereas incubation with sHLA-G may have a counterbalancing effect, creating an anti-inflammatory environment due to the release of interleukin (IL)-10 (9, 10). Based on these findings, it has been recently proposed that HLA-G should be categorized as an "immune checkpoint" molecule (2).

\section{HLA-G+ IMMUNE CELLS IN PHYSIOLOGIC CONDITIONS}

\section{T and NK Cells}

Immune tolerance is based on a complex series of mechanisms that ultimately facilitate the elimination of foreign antigens, preventing collateral damage to host tissues. Immune tolerance is broadly classified into central and peripheral tolerance. Central tolerance occurs during lymphocyte development in the primary lymphoid organs, namely thymus (T cells) and bone marrow (B cells). Peripheral tolerance takes place in the peripheral tissues and lymph nodes, and consists of different immunologic mechanisms capable of controlling self-reactive lymphocytes that have escaped from central deletion (11). Immune regulation is crucial in the maintenance of peripheral tolerance 
and is mediated by the action of $\mathrm{T}$ regulatory (Treg) lymphocytes (12). Several subsets of Treg lymphocytes with distinct phenotypes and mechanisms of action have been described within both CD4+ and CD8 $+\mathrm{T}$ lymphocytes, and it has been clearly demonstrated that these cells play an important role in physiological and pathological conditions such as autoimmune, infectious, or neoplastic diseases $(12,13)$.

In 2007 Feger et al. described novel subsets of $\mathrm{T}$ cells that express the immunomodulatory molecule HLA-G, identifying them as distinct subpopulations of Treg lymphocytes (14). In recent years, many other studies have confirmed the importance of HLA-G+ Treg lymphocytes in physiology and disease. Similar to the classical CD4+CD25+FoxP3+Tregs, human HLA-G+ Treg cells originate from thymus and are present in variable percentages in the peripheral blood of healthy subjects (0.1-8.3\%). However, HLA-G+ Treg cells can be differentiated from classical CD4+ Tregs on the basis of their distinctive phenotype, lacking Forkhead Box P3 (FoxP3), CD39, and CD25 expression (14). CD4+HLA-G+T cells have a low proliferative capacity that, differently from classic Tregs, cannot be overcome by the addition of exogenous IL-2 (14). In vitro, CD4+HLAG+ Tregs inhibit T-cell responses mainly through cell-to-cell contact and independent mechanisms (15); whereas classical CD4+CD25+FoxP3+ Tregs exert their suppressive function mainly through cell-to-cell dependent mechanisms $(13,16)$. In both Tregs subpopulations suppressive activity depends on an optimal TCR stimulation. CD4+HLA-G+ Tregs and classical CD4+CD25+FoxP3+ Tregs share common intracellular down-stream signaling events, following $\mathrm{T}$ cell receptor (TCR) ligation $(17,18)$. They show altered activation of the linker in activation of $\mathrm{T}$ cells (LAT) molecules involved in proximal TCR signaling, leading to reduced intracellular calcium influx when compared to non-regulatory T-cells (16). CD4+HLA-G+ Treg cells seem to exert their suppressive function via the secretion of various tolerogenic molecules such as sHLA-G5, IL-10, IL-35, and transforming growth factor (TGF)- $\beta(15,16)$. In this context, IL-10 and sHLA-G5 are the most important molecules responsible for the immunoregulatory activity of the CD $4+$ HLA-G+ Treg $(15,16)$. Transforming growth factor- $\beta$ and IL-35 do not seem to have a direct role in the immunomodulation exerted by CD4+HLA-G+ Treg, nevertheless, these cytokines may indirectly promote an immunosuppressive milieu, influencing the local differentiation of peripherally induced Tregs and/or supporting the survival of thymus-derived natural Tregs (19-21).

In vitro, CD4+HLA-G+ Tregs display a less efficient suppressive activity than classical $\mathrm{CD} 4{ }^{+} \mathrm{CD} 25^{+}$FoxP $3{ }^{+}$Tregs; whereas in vivo the immunosuppressive capacity of the two Treg subsets is comparable (16). This notion suggests that CD4+HLAG+ Tregs may modulate tissue inflammation within the target organs, in close proximity to effector T cells $(16,22)$.

Besides thymus-derived HLA-G+ Tregs, some normal resting and activated $\mathrm{CD}^{+}$and $\mathrm{CD}^{+}{ }^{+} \mathrm{T}$ cells may acquire through trogocytosis the HLA-G1 molecule from antigen presenting cells (APCs), thus changing their function from effectors to regulatory cells capable of inhibiting alloproliferative responses (23). Interestingly, the acquisition of HLA-G via trogocytosis has also been described for monocytes and NK cells $(24,25)$. A noncytolytic subset of HLA-G+ NK cells (NK-ireg) can be generated in vitro from peripheral blood $\mathrm{CD} 34+$ hematopoietic progenitors expressing membrane-bound IL-15. NK-ireg cells display a mature NK cell phenotype, release suppressive molecules (HLAG, IL-10, and IL-21), and through these factors are capable of suppressing the cytotoxicity of DC and NK cells (26).

It has been recently reported that neutrophil gelatinaseassociated lipocalin seems to be capable of upregulating HLA-G expression and expansion of Tregs cells in healthy donors (27). This observation is consistent with the knowledge that lipocalin family members act as modulators of many different physiological and pathologic processes, including cell differentiation, proliferation and apoptosis (28). Moreover, HLA$\mathrm{G}$ expression is strongly regulated by methylation, and it has been recently observed that hypomethylating agents such as azacytidine and decitabine, can induce de novo expression of HLA-G on conventional $\mathrm{T}$ cells thus converting the latter into HLA-G+ Tregs (29). This data suggest the possibility of modulating the expansion of HLA-G-expressing $\mathrm{T}$ cells in vivo or generating them in vitro for adoptive immunotherapy in transplant patients or for other immunological disorders.

\section{Monocytes}

The expression of HLA-G in human mononuclear phagocytes and APC has been known for many years $(30,31)$. HLA-G cell surface expression has been detected at variable percentages in peripheral blood CD14+ monocytes from healthy individuals (32-36). HLA-G mRNA and intracellular HLA-G levels as well as surface HLA-G expression are selectively increased after in vitro treatment of monocytes with interferon (IFN) $-\beta$, IFN- $\gamma$, and IL-10 (30, 32).

As far as the functional role of CD14+HLA-G+ cells is concerned, it has been reported that they have limited in vitro immunostimulatory function and are able to inhibit T-cell alloproliferation when added in mixed lymphocyte cultures. The suppressive function of CD14+HLA-G+ cells is related to the expression of the HLA-G molecule, which can be antagonized by blocking HLA-G with specific monoclonal antibodies, and may also be mediated through sHLA-G, as suggested by transwell experiments. Further in vitro experiments have shown that coincubation of CD4+ and CD8 + T cells with CD14+HLA-G+ cells decreases the surface expression of CD4 and CD8 molecules and inhibits both Th1 and Th2 cytokine production by antigenstimulated autologous $\mathrm{CD} 4^{+} \mathrm{T}$ cells $(37,38)$.

Monocytes can differentiate into a range of functional subsets including pro-inflammatory (M1) and anti-inflammatory (M2) cells. Recently published data indicates that M2 cells obtained from peripheral blood monocytes after in vitro activation with IL-4, express high amounts of HLA-G and drive upregulation of the HLA-G ligand immunoglobulin-like transcript (ILT)-2 on NK cells. This leads to the generation of hyporesponsive CD56 $\mathrm{dim}$ NK cells with limited degranulation and cytotoxic activity (39).

\section{Dendritic Cells}

Peripheral blood DCs are APCs that regulate innate and adaptive immune responses. Different DC subsets have been 
identified that can drive immune responses toward immunity or tolerance, including conventional monocytoid DCs that maintain immunological homeostasis and can induce tolerance, plasmacytoid DCs that present foreign antigens, activate Tregs, and tolerogenic DCs which promote tolerance.

The expression of HLA-G on DC may be regulated by cytokines. In vitro experiments have shown that TGF- $\beta$ increases HLA-G expression by DC and that HLA-G+ DC down-regulate activation of CD4+ $\mathrm{T}$ cells and production of IL-6 and IL17 , suggesting the possibility that HLA-G+ DC plays a role in immunoregulatory in vivo (40).

Recently, a subset of human DC has been characterized. Termed DC-10, these human DC have the ability to secrete IL-10. DC-10 are found in peripheral blood and the spleen of healthy individuals. They can be generated in vitro by culturing peripheral monocytes in the presence of IL-10. Furthermore, DC10 are highly represented in the decidua of pregnant women when compared to peripheral blood, suggesting that these cells may accumulate at the fetal maternal interface to promote tolerance to the semi-allogeneic fetus (41). DC-10 have a mature phenotype and express CD11c, CD14, CD16, CD141, and CD163. DC-10 also express HLA-G and ILT-4 and are able to induce T regulatory type 1 ( $\operatorname{Tr} 1$ ) cells. The amount of HLA-G expression on DC-10 is genetically driven and is associated with specific variations in the 3' untranslated region of the HLA-G gene. Of particular interest are findings on the capacity of DC-10 to induce $\operatorname{Tr} 1$ cells, which correlates with the level of HLA-G expression. These data indicate that HLA-G expression plays a fundamental role in the tolerogenic activity of DC-10 and suggest a potential clinical use of $\mathrm{DC}-10$ as an immunomodulatory treatment (42-44).

Collectively, results of in vitro and in vivo experiments indicate that HLA-G positive DC can affect the activity of NK cells, modulate the response of effector $\mathrm{CD} 4+$ and $\mathrm{CD} 8+\mathrm{T}$ cells, and induce Tregs. These findings strongly support the notion that HLA-G expression by DC plays a central role modulating innate and adaptive immune responses in a healthy state and in pathological conditions.

\section{HLA-G-EXPRESSING IMMUNE CELLS IN NON-AUTOIMMUNE DISEASES}

\section{T and NK Cells}

Lymphocytes expressing HLA-G have been reported in several diseases in which the immune system plays a pivotal role, such as neoplastic, infectious, and autoimmune/inflammatory disorders.

An increase in the percentage of CD8+HLA-G+ T cells and the presence of HIV-1-specific CD8+HLA-G+ T lymphocytes have been described in HIV-1 patients, although their exact pathophysiologic role in the disease is still elusive (36, 45, 46). Other authors observed that HLA-G+ Treg may reduce harmful bystander immune activation, while minimally inhibiting antiviral $\mathrm{T}$ cell-mediated responses, thus suggesting the positive role of these cells in the natural history of HIV infection (47).
Reduced percentages of HLA-G expressing $\mathrm{T}$ cells and monocytes have been observed in pre-eclamptic patients, compared with women with a healthy pregnancy or healthy control subjects (48). By analogy with these results, Hsu and colleagues reported that CD4+HLA-G $+\mathrm{T}$ cells are significantly expanded in the peripheral blood of pregnant women compared with non-pregnant controls and pre-eclamptic women (49). In addition, CD4+HLA-G+ T cells tend to accumulate in the decidua of healthy pregnant women; whereas this phenomenon is impaired in pre-eclamptic patients (41). A small subset of NKp46+HLA-G+IL-10+ NK cells has been described in vivo among the decidual NK cells of pregnant women, but the exact role of this cell subset requires further investigation (26).

Recently, a novel population of CD $4{ }^{\text {low } H L A-G}+\mathrm{T}$ cells, identified as IL-4-expressing Th17 cells, has been described in prostate cancer and their expansion seems to correlate with the increase of tumor aggressiveness (50). Increased percentages of HLA-G+CD3+ cells have been observed in the peripheral blood of breast cancer patients, suggesting that these cells may contribute to tumor development by down-modulating antitumor immunity (51). Moreover, it has also been reported that a subset of HLA-G + NK cells possessing suppressive activity are considerably increased in the peripheral blood of breast cancer patients (52).

It is well-known that, in order to escape immune-surveillance, various malignant cells can aberrantly express HLA-G and/or secrete sHLA-G $(53,54)$. In addition, cancer cells can induce HLA-G-expressing immune cells (e.g., transferring HLA-G to $T$ cells through trogocytosis) within the tumor microenvironment. This mechanism may increase the number of local immunosuppressive cells, thus facilitating tumor immuneescape $(23,55,56)$.

A similar mechanism of immune-evasion has also been described for microbial infections, in fact Pseudomonas aeruginosa seems to be capable, at least in vitro, of inducing HLA-G expression in immune cells, creating a protected niche and facilitating bacterial survival (57).

In the context of kidney transplants, it has been reported that HLA-G expression on T cells increases after the transplant, but significantly decreases in subjects experiencing an acute rejection. This data suggests that HLA-G might be involved in the protection of transplants against rejection and the levels of HLA-G on CD4+ may represent a potential marker in predicting episodes of renal rejection after kidney transplantation $(58,59)$.

In patients that experience an allergic reaction, HLA-G expression as well as sHLA-G secretion are increased in CD4+ cells and monocytes after in vitro stimulation by the causal allergen, but not by non-specific stimuli and non-causal allergens (60). This data suggest that HLA-G may be involved into the pathogenetic mechanisms underlying allergic inflammation and allergen specific immunotherapy $(60,61)$.

\section{Monocytes and Dendritic Cells}

Several in vivo data-sets support the immunomodulatory properties of HLA-G+ monocytes. In fact, a high frequency of CD14+HLA-G+ cells have been detected in patients undergoing allogeneic hematopoietic cell transplantation. These HLA-G+ 
monocytes appear early post-transplant and remain at high levels for up to one year after the transplant. It is of interest that HLA-G+ monocytes have also been detected in skin biopsies of transplanted patients who developed graft-versus-host disease. It may be hypothesized that the increase of HLA-G+ monocytes could be related to an alloreaction occurring after transplant (37).

Elevated numbers of HLA-G+ monocytes have been found in the peripheral blood of HIV-1-infected individuals. The expression of HLA-G might either be directly caused by the HIV1 virus infection or indirectly related to increased levels of IL-10, which is known to induce HLA-G expression in monocytes. By decreasing the antigen-presenting capacity of monocyte, the upregulated expression of HLA-G could be one of the strategies used by the HIV-1 virus to evade immune surveillance (36).

Collectively, in vitro and in vivo data suggests that monocyte activation by cytokines, infectious agents, and allogeneic stimuli induces HLA-G expression. Taking this into account, HLA$\mathrm{G}+$ monocytes may exert immunosuppressive effects on CD4+, $\mathrm{CD} 8+$, and NK cells, playing a role in down-regulation of the immune response.

Concerning DCs, it has been reported that monocytoid DC expressing high HLA-G levels can be found in the peripheral blood of stable and tolerant liver transplant recipients. The number of HLA-G+ DC correlates with the percentage of CD4+CD25 ${ }^{\text {high }}$ CD127- Tregs and with the intensity of Foxp3 expression, thus supporting the hypothesis that HLA-G+ DC may play a tolerogenic role in alloimmune reactivity (62).

\section{Mast Cells}

Mast cells are bone marrow derived cells that circulate in an immature form and become mature after migration in a tissue site. Mast cells have been mostly viewed as effectors of IgEmediated allergic diseases and host defense against parasites. The role of mast cells in both innate and adaptive immunity has been recognized recently. In addition, mast cells are involved in tissue repair through the secretion of several cytokines and growth factors that enhance fibroblast proliferation and collagen deposition, and inhibit degradation of the extra cellular matrix (63).

To our present knowledge it is not known whether mast cells express HLA-G in physiological conditions, and emerging research on the role for HLA-G+ mast cells in liver diseases is of interest $(64,65)$. It has been reported that mast cells infiltrating the livers of patients infected with hepatitis $C$ virus (HCV) express HLA-G and secrete HLA-G in soluble form. The number of HLA-G+ mast cells is significantly associated with the areas of connective tissue and liver fibrosis located close to the hepatic arteries, veins and bile ducts of the portal tracts (66, 67). The presence of mast cells in the liver can be related to the production of TGF- $\beta$, a potent mast cell chemoattractant, by hepatic stellate cells (HSC) $(68,69)$. Then, HLA-G+ infiltrating mast cells promote HSC proliferation that, in turn, induces liver fibrosis (70). The expression and secretion of HLA-G by mast cells in HCV infected patients can be explained by the elevated amounts of IFN- $\alpha$ and IL-10 produced during HCV infection $(71,72)$. Accordingly, in vitro and in vivo data indicate that these cytokines strongly modulate HLA-G up-regulation in monocytes and other cells including trophoblasts, fibroblasts, and neoplastic cells $(32,73-78)$. The function of HLA-G+ mast cells during $\mathrm{HCV}$ infection remains to be clarified. It may be suggested that HLA-G expression may promote viral escape from the immune system by inhibiting both adaptive and innate immunity, thus protecting HCV-infected cells and favoring viral progression.

In summary, this data supports the assumption that HLAG+ immune cells are implicated in the pathogenesis of a wide array of disorders. The role of HLA-G+ immune cells in the context of autoimmune diseases will be discussed in the following paragraphs.

\section{HLA-G-EXPRESSING IMMUNE CELLS IN AUTOIMMUNE DISEASES}

\section{Multiple Sclerosis}

Multiple sclerosis (MS) is an immune-mediated disorder of the central nervous system (CNS) leading to demyelination as well as axonal and neuronal damage, with progressive neurological impairment (79). The course of MS can follow four clinical patterns that include relapsing remitting MS (RRMS, which accounts for $80-90 \%$ of MS cases at onset), secondary progressive MS (SPMS), primary progressive MS (PPMS), and progressive relapsing MS (PRMS) (80). Although the pathogenesis of MS is still not completely understood, it is known that central tolerance may be defective leading to the development of self-reactive $\mathrm{T}$ cells that transmigrate into the CNS where they can be activated by APCs and determine brain damage (79). The brain has long been considered an immunologically privileged site. This idea is based on the observation that tissue transplants in the CNS are not commonly rejected by the immune system. Commonly accepted explanations for the lack of an effective immune response to antigens in the brain are an anti-inflammatory and, with regard to invading immune cells, pro-apoptotic environment in the brain, the limited access of brain-derived antigens to the lymphoid organs, the presence of the bloodbrain barrier, low major histocompatibility complex (MHC) expression in the brain parenchyma, and the absence of DCs (81, 82). However, numerous studies in infectious, autoimmune and tumor models have challenged this view by showing that potent immune reactions can and do occur in the CNS (83).

The main aspect favoring the autoimmune etiology of MS consists of the presence of activated IFN-producing $\mathrm{T}$ helper 1 (Th1) cells, that recognize peptides of the myelin sheath, including myelin basic protein (MBP), proteolipid protein (PLP), and myelin oligodendrocyte glycoprotein (MOG) (80). HLA-G immunoreactivity was detected in the transition zone between the plaque center and the perilesional areas as well as in both acute and chronic active plaques. In proximity of MS lesions the adjacent normal appearing gray matter remained predominantly negative for HLA-G, whereas HLA$G$ expression in adjacent normal appearing white matter was similar to the expression levels of the lesion borders (83). Notably, in early and highly inflammatory MS lesions, HLA-G expression was abundant and detected on macrophages/activated 
microglia cells. Similarly, perilesional activated microglia cells were immunoreactive for HLA-G. Furthermore, endothelial cells and meningeal vessels as well as arachnoidal cap cells show HLA-G immunoreactivity (83). However, expression of the inhibitory receptors for HLA-G, belonging to immunoglobulinlike transcript family ILT2 and ILT4, have been described in chronic active MS plaques. ILT2 immunoreactivity could be observed in the plaque center and the plaque border and paralleled HLA-G immunoreactivity. The main cellular sources for both molecules were macrophages and microglia (83). The cerebrospinal fluid (CSF) compartment has been proposed to partially constitute a functional equivalent of the lymphatic system for the CNS. Interestingly, the levels of HLA-G on $\mathrm{CD}_{14}{ }^{+}$monocytes were significantly elevated in the CSF of patients with MS compared with peripheral blood. Of note is the fact that HLA-G expressed by monocytes was identified as an important negative immune-regulatory factor, down-regulating the production of Th1 as well as Th2 cytokines, inhibiting antigen-specific and autologous $\mathrm{CD} 4{ }^{+}$T-cell activation, and inducing anergic $\mathrm{T}$ cells $(37,38)$. Furthermore, a small number of both $\mathrm{CD}^{+}$and $\mathrm{CD}^{+} \mathrm{T}$ cells, including $\mathrm{CD} 4{ }^{+}$ Tregs, expressed HLA-G in the CSF of MS patients (83). Interestingly, CSF-derived HLA-G+CD4+ Tregs show high expression of the $\mathrm{C}-\mathrm{C}$ chemokine receptor 5 that might favor their selective migration into the nervous system of MS patients, counteracting the activity of autoreactive $\mathrm{T}$ cells. The frequency of CSF-derived HLA-G+CD4+ Tregs correlates positively with the disease status in MS patients with active disease (22). Increased levels of HLA-G+CD4+ Tregs have been detected in MS patients responses to IFN or natalizumab treatment (80).

Taken together, these findings, seem to confirm that HLA-G expression on immune cells infiltrating CNS and detectable in CSF, may contribute to immune-regulation in MS.

\section{Systemic Lupus Erythematosus}

Systemic lupus erythematosus (SLE) is an autoimmune inflammatory disease that can affect virtually any organ system, including skin, joints, kidneys, brain, and blood vessels (84). The development of SLE is dependent on a complex interplay between genetic, environmental, and immunological factors (85, 86). Among these, defective function of regulatory $\mathrm{T}$ cells and polyclonal activation of $\mathrm{B}$ lymphocytes leading to the production of auto-antibodies seems to play a major role (87-89).

Limited literature data are available on the expression of HLA-G in immune cells from SLE patients. Monsivais-Urenda et al. reported that monocytes from SLE patients as well as mature $\mathrm{CD}^{+} 3^{+} \mathrm{DC}$ showed a reduced expression of HLA-G compared with healthy controls (35). In addition, monocytes from SLE patients showed a diminished induction of HLA-G expression in response to stimulation with IL-10, and when pre-treated with IFN- $\gamma$ they exhibited an impaired capability to inhibit the proliferation of autologous lymphocytes. Interestingly, lymphocytes from SLE patients seem to display a lower capability to acquire HLA-G molecules by trogocytosis from autologous monocytes as compared to lymphocytes from normal subjects (35). By contrast, our and other groups reported that the percentage of HLA-G expressing cells among PBMC is significantly higher in SLE patients than in healthy controls (33, 90). In particular, the percentages of HLA-G-positive monocytes and HLA-G-expressing CD4+, CD8+, and CD4+/CD8+ double positive (DP) cells are significantly higher in SLE patients than in controls. Moreover, within the population of DP cells a subpopulation of $\mathrm{CD} 4{ }^{\text {dull }} \mathrm{CD} 8^{\text {high }}$ cells displayed a high proportion of HLA-G ${ }^{+}$cells, while HLA-G was virtually absent in the same subpopulation of healthy subjects (33). The function of circulating HLA-G+ DP cells is not known, however, it is worth noting that DP cells seem to exert a suppressive role in the production of autoantibodies in SLE patients (91). In summary, it may be proposed that the up-regulation of HLA-G membrane expression by PBMC could reflect an effort to regulate the hyperactive immune status occurring in SLE.

\section{Systemic Sclerosis}

Systemic sclerosis (SSc) is a chronic connective tissue disease of unknown origin, more frequently affecting women. It is characterized by diffuse fibrosis, vasculopathy and immune dysregulation. In addition to skin involvement, SSc can affect multiple organ systems, including the musculo-skeletal, pulmonary, cardiac, gastrointestinal, and urinary systems (92, 93). Complex alterations of the normal functional balance within immune cells sub-populations, in particular Th17 lymphocytes and Tregs, including both CD4+ and CD8+ Tregs subsets, have been demonstrated in patients affected by SSc (94-97).

Our research group analyzed the role of both membrane HLA$\mathrm{G}$ and sHLA-G in SSc patients. In particular, we recently reported that the percentage of HLA-G-positive monocytes, CD4+ T cells, CD8 $+\mathrm{T}$ cells and DP cells are significantly higher in SSc patients as compared to healthy subjects (34). Among DP cells a subpopulation of $\mathrm{CD} 4^{d u l l} \mathrm{CD} 8^{\text {high }}$ lymphocytes highly expressing HLA-G was detected. The function of circulating $\mathrm{DP}$ cells in SSc is under investigation, however, it is worth noting that these cells, which may exert potent suppressive effects, are present in the inflamed tissues of patients affected by immune mediated disorders and in the skin of patients with early active SSc. This may contribute, through IL-4 secretion, to the enhanced extracellular matrix deposition by fibroblasts (98). Plasma sHLA-G levels were higher in SSc patients when compared to healthy controls. Notably, plasma levels of sHLA-G1 and sHLA-G5 isoforms were comparable and no significant differences were detected in total sHLAG, sHLA-G1 and sHLA-G5 levels between limited and diffuse SSc forms. The total sHLA-G plasma levels correlated with the elevated TGF- $\beta$ levels circulating in SSc patients (34). This finding is in agreement with in vitro data demonstrating that the production of TGF- $\beta$ by myelomonocytic cells is strongly increased after incubation with recombinant sHLA-G (99). In summary, it may be proposed that there is a possible involvement of $\mathrm{HLA}-\mathrm{G}$ in SSc pathogenesis, as the elevated HLA-G membrane expression by PBMC and the increased sHLA-G plasma levels may reflect an attempt to control the immune derangement occurring in this disease and concur, through TGF- $\beta$ up-regulation, with fibroblast activation and fibrosis development (34). 


\section{Skin Diseases}

Psoriasis (Ps) is a common inflammatory, chronic, and disabling skin disease that affects $1-3 \%$ of the population (100). Distinct clinical phenotypes may be observed in this disease, including chronic plaque (Ps vulgaris), guttate, and pustular variants. At least $10 \%$ of patients can develop arthritis (101). In many cases, a marked infiltration of mononuclear leucocytes ( $T$ lymphocytes and DC) into the dermis and elongated/hyperplastic blood vessels in the papillary dermal region can be observed (102). Because Ps is considered to be an organ-specific autoimmune disease, Cardili et al. analyzed HLA-G expression in skin specimens obtained from patients with Ps and observed the presence of HLA-G molecules on lymphomononuclear cells within the dermis and to a higher extent, in the epidermis. The intensity of HLA-G expression was not correlated with Ps variants or severity. By contrast, skin specimens obtained from healthy individuals were negative for HLA-G expression (103). Other authors have reported HLA-G expression in $\mathrm{CD}^{+}{ }^{+} \mathrm{CD} 11 \mathrm{c}^{+}$ macrophages lining the dermo-epidermal junction in patients with Ps vulgaris (104). In addition, NK cells and $\mathrm{CD}^{+} \mathrm{T}$ cells expressing the IL2 inhibitory receptor have been described in Ps skin infiltrates, suggesting that HLA-G may act as an inhibitory molecule to down-regulate the activation of effector cells (104). These findings lead to the assumption that HLA$\mathrm{G}^{+}$macrophages could represent an internal control system that counteracts auto-reactive expression of T-cell cognate receptors for HLA-G.

Atopic dermatitis $(\mathrm{AD})$ is another chronic T-cell mediated skin disorder which, in contrast to Ps, exhibits a Th2 type cytokine profile including over-production of IL-10, which is known to up-regulate HLA-G (105). Khosrotehrani et al. investigated the role of HLA-G in patients with AD. They found that HLA-G was mainly expressed by infiltrating $\mathrm{T}$ cells and to a lesser extent, by macrophages and even DC (106). The epidermis was consistently negative for HLA-G expression, suggesting that, analogously to Ps, HLA-G up-regulation may either be the consequence of the permissive cytokine environment in $\mathrm{AD}$ or it may be a part of an internal regulatory system to control excessive inflammation.

\section{REFERENCES}

1. Gonzalez A, Rebmann V, LeMaoult J, Horn PA, Carosella ED, Alegre E. The immunosuppressive molecule HLA-G and its clinical implications. Crit Rev Clin Lab Sci. (2012) 49:63-84. doi: 10.3109/10408363.2012.67 7947

2. Carosella ED, Rouas-Freiss N, Tronik-Le Roux D, Moreau P, LeMaoult J. HLA-G: an immune checkpoint molecule. Adv Immunol. (2015) 127:33-144. doi: 10.1016/bs.ai.2015.04.001

3. Lila N, Rouas-Freiss N, Dausset J, Carpentier A, Carosella ED. Soluble HLA-G protein secreted by allo-specific CD4+ T cells suppresses the allo-proliferative response: a CD4+ T cell regulatory mechanism. Proc Natl Acad Sci USA. (2001) 98:12150-5. doi: 10.1073/pnas.201407398

4. Contini P, Ghio M, Poggi A, Filaci G, Indiveri F, Ferrone S, et al. Soluble HLA-A,-B,-C and -G molecules induce apoptosis in T and NK CD8+ cells and inhibit cytotoxic T cell activity through CD8 ligation. Eur J Immunol. (2003) 33:125-34. doi: 10.1002/immu.200390015

5. Le Friec G, Laupeze B, Fardel O, Sebti Y, Pangault C, Guilloux V, et al. Soluble HLA-G inhibits human dendritic cell-triggered allogeneic T-cell proliferation

\section{DISCUSSION}

Data in recent literature indicates that small percentages of HLA$\mathrm{G}$ positive immune cells can be detected in the peripheral blood of patients with physiological conditions. In these conditions HLA-G positive immune cells seem to play an emerging role in maintaining immune homeostasis. However, increased percentages of circulating and tissue infiltrating HLA-G positive immune cells occur in various pathological conditions like infections, cancers, transplants, and immune-mediated diseases. Taking into account the immunoregulatory role of HLA-G, it may be suggested that T lymphocytes, NK cells and APCs that express HLA-G molecules are potentially involved in the pathogenesis of immune mediated diseases.

HLA-G positive cells can modulate both the priming and the effector phases of the immune response, thus contributing to peripheral immune tolerance. It may be proposed that HLA$\mathrm{G}$ expressing immune cells represent an attempt to create an immune-suppressive milieu, as a way of controlling immune derangement in systemic autoimmune disorders. However, several important issues still need to be clarified in this context. A better understanding of the HLA-G gene regulation will greatly improve the possibility of manipulating this emerging immune check-point, which could alter the course of immunological diseases. Moreover, the role played by different molecular HLA$\mathrm{G}$ isoforms and the contribution of specific HLA-G expressing subpopulations in each clinical situation needs to be better defined. Therefore further pre-clinical and clinical investigations are required in order to provide more detailed information on the role played by HLA-G expressing cells in the mechanisms underlying the onset and progression of immune-mediated diseases. These future studies are crucial for the development of potential HLA-G strategies of therapy.

\section{AUTHOR CONTRIBUTIONS}

All authors equally contributed to the conception of ideas and design of this manuscript.

without altering dendritic differentiation and maturation processes. Hum Immunol. (2003) 64:752-61. doi: 10.1016/S0198-8859(03)00091-0

6. Naji A, Menier C, Morandi F, Agaugue S, Maki G, Ferretti E, et al. Binding of HLA-G to ITIM-bearing Ig-like transcript 2 receptor suppresses B cell responses. J Immunol. (2014) 192:1536-46. doi: 10.4049/jimmunol.1300438

7. Contini P, Ghio M, Merlo A, Poggi A, Indiveri F, Puppo F. Apoptosis of antigen-specific T lymphocytes upon the engagement of CD8 by soluble HLA class I molecules is Fas ligand/Fas mediated: evidence for the involvement of p56lck, calcium calmodulin kinase II, and Calcium-independent protein kinase C signaling pathways and for NF-kappaB and NF-AT nuclear translocation. J Immunol. (2005) 175:7244-54. doi: 10.4049/jimmunol.175.11. 7244

8. Fournel S, Aguerre-Girr M, Huc X, Lenfant F, Alam A, Toubert A, et al. Cutting edge: soluble HLA-G1 triggers CD95/CD95 ligand-mediated apoptosis in activated CD8+ cells by interacting with CD8. J Immunol. (2000) 164:6100-4. doi: 10.4049/jimmunol.164.12.6100

9. Kanai T, Fujii T, Unno N, Yamashita T, Hyodo H, Miki A, et al. Human leukocyte antigen-G-expressing cells differently modulate the release of cytokines from mononuclear cells present in the decidua versus peripheral 
blood. Am J Reprod Immunol. (2001) 45:94-9. doi: 10.1111/j.8755-8920.2001. 450205. $\mathrm{x}$

10. Kanai T, Fujii T, Kozuma S, Yamashita T, Miki A, Kikuchi A, et al. Soluble HLA-G influences the release of cytokines from allogeneic peripheral blood mononuclear cells in culture. Mol Hum Reprod. (2001) 7:195-200. doi: 10 . 1093/molehr/7.2.195

11. Conteduca G, Indiveri F, Filaci G, Negrini S. Beyond APECED: an update on the role of the autoimmune regulator gene (AIRE) in physiology and disease. Autoimmun Rev. (2018) 17:325-30. doi: 10.1016/j.autrev.2017.10.017

12. Negrini S, Fenoglio D, Parodi A, Kalli F, Battaglia F, Nasi G, et al. Phenotypic alterations involved in CD8+ Treg impairment in systemic sclerosis. Front Immunol. (2017) 8:18. doi: 10.3389/fimmu.2017.00018

13. Zhao H, Liao X, Kang Y. Tregs: where we are and what comes next? Front Immunol. (2017) 8:1578. doi: 10.3389/fimmu.2017.01578

14. Feger U, Tolosa E, Huang YH, Waschbisch A, Biedermann T, Melms A, et al. HLA-G expression defines a novel regulatory T-cell subset present in human peripheral blood and sites of inflammation. Blood. (2007) 110:568-77. doi: 10.1182/blood-2006-11-057125

15. Huang YH, Zozulya AL, Weidenfeller C, Schwab N, Wiendl H. T cell suppression by naturally occurring HLA-G-expressing regulatory CD4+ T cells is IL-10-dependent and reversible. J Leukoc Biol. (2009) 86:273-81. doi: 10.1189/jlb.1008649

16. Pankratz S, Bittner S, Herrmann AM, Schuhmann MK, Ruck T, Meuth SG, et al. Human CD4+ HLA-G+ regulatory T cells are potent suppressors of graftversus-host disease in vivo. FASEB J. (2014) 28:3435-45. doi: 10.1096/fj.14251074

17. Tsang JY, Camara NO, Eren E, Schneider H, Rudd C, Lombardi G, et al. Altered proximal $\mathrm{T}$ cell receptor (TCR) signaling in human $\mathrm{CD} 4+\mathrm{CD} 25+$ regulatory T cells. J Leukoc Biol. (2006) 80:145-51. doi: 10.1189/jlb.0605344

18. Crellin NK, Garcia RV, Levings MK. Altered activation of AKT is required for the suppressive function of human $\mathrm{CD} 4+\mathrm{CD} 25+\mathrm{T}$ regulatory cells. Blood. (2007) 109:2014-22. doi: 10.1182/blood-2006-07-035279

19. Hadaschik EN, Enk AH. TGF-betal-induced regulatory T cells. Hum Immunol. (2015) 76:561-4. doi: 10.1016/j.humimm.2015.06.015

20. Huang A, Cheng L, He M, Nie J, Wang J, Jiang K. Interleukin- 35 on B cell and T cell induction and regulation. J Inflamm. (2017) 14:16. doi: 10.1186/s12950017-0164-5

21. Ghio M, Contini P, Negrini S, Mazzei C, Zocchi MR, Poggi A. Down regulation of human natural killer cell-mediated cytolysis induced by blood transfusion: role of transforming growth factor-beta(1), soluble Fas ligand, and soluble Class I human leukocyte antigen. Transfusion. (2011) 51:1567-73. doi: 10. 1111/j.1537-2995.2010.03000.x

22. Huang YH, Zozulya AL, Weidenfeller C, Metz I, Buck D, Toyka KV, et al. Specific central nervous system recruitment of HLA-G(+) regulatory T cells in multiple sclerosis. Ann Neurol. (2009) 66:171-83. doi: 10.1002/ana.21705

23. LeMaoult J, Caumartin J, Daouya M, Favier B, Le Rond S, Gonzalez A, et al. Immune regulation by pretenders: cell-to-cell transfers of HLA-G make effector T cells act as regulatory cells. Blood. (2007) 109:2040-8. doi: 10.1182/ blood-2006-05-024547

24. HoWangYin KY, Alegre E, Daouya M, Favier B, Carosella ED, LeMaoult J. Different functional outcomes of intercellular membrane transfers to monocytes and T cells. Cell Mol Life Sci. (2010) 67:1133-45. doi: 10.1007/ s00018-009-0239-4

25. Caumartin J, Favier B, Daouya M, Guillard C, Moreau P, Carosella ED, et al. Trogocytosis-based generation of suppressive NK cells. EMBO J. (2007) 26:1423-33. doi: 10.1038/sj.emboj.7601570

26. Giuliani M, Giron-Michel J, Negrini S, Vacca P, Durali D, Caignard A, et al. Generation of a novel regulatory NK cell subset from peripheral blood CD34+ progenitors promoted by membrane-bound IL-15. PLoS One. (2008) 3:e2241. doi: 10.1371/journal.pone.0002241

27. La Manna G, Ghinatti G, Tazzari PL, Alviano F, Ricci F, Capelli I, et al. Neutrophil gelatinase-associated lipocalin increases HLA-G(+)/FoxP3(+) T-regulatory cell population in an in vitro model of PBMC. PLoS One. (2014) 9:e89497. doi: 10.1371/journal.pone.0089497

28. Costa D, Biticchi R, Negrini S, Tasso R, Cancedda R, Descalzi F, et al. Lipocalin2 controls the expression of SDF- 1 and the number of responsive cells in bone. Cytokine. (2010) 51:47-52. doi: 10.1016/j.cyto.2010.02.009
29. Stamou P, Marioli D, Patmanidi AL, Sgourou A, Vittoraki A, Theofani E, et al. Simple in vitro generation of human leukocyte antigen-G-expressing T-regulatory cells through pharmacological hypomethylation for adoptive cellular immunotherapy against graft-versus-host disease. Cytotherapy. (2017) 19:521-30. doi: 10.1016/j.jcyt.2017.01.004

30. Yang Y, Chu W, Geraghty DE, Hunt JS. Expression of HLA-G in human mononuclear phagocytes and selective induction by IFN-gamma. J Immunol. (1996) 156:4224-31.

31. LeMaoult J, Krawice-Radanne I, Dausset J, Carosella ED. HLA-G1-expressing antigen-presenting cells induce immunosuppressive CD4+ T cells. Proc Natl Acad Sci USA. (2004) 101:7064-9. doi: 10.1073/pnas.0401922101

32. Moreau P, Adrian-Cabestre F, Menier C, Guiard V, Gourand L, Dausset J, et al. IL-10 selectively induces HLA-G expression in human trophoblasts and monocytes. Int Immunol. (1999) 11:803-11. doi: 10.1093/intimm/11.5.803

33. Negrini S, Contini P, Pupo F, Greco M, Murdaca G, Puppo F. Expression of membrane-bound human leucocyte antigen-G in systemic sclerosis and systemic lupus erythematosus. Hum Immunol. (2020) 81:162-7. doi: 10.1016/ j.humimm.2019.12.004

34. Contini P, Negrini S, Murdaca G, Borro M, Puppo F. Evaluation of membranebound and soluble forms of human leucocyte antigen-G in systemic sclerosis. Clin Exp Immunol. (2018) 193:152-9. doi: 10.1111/cei.13134

35. Monsivais-Urenda AE, Baranda L, Alvarez-Quiroga C, Abud-Mendoza C, Gonzalez-Amaro R. Expression and functional role of HLA-G in immune cells from patients with systemic lupus erythematosus. J Clin Immunol. (2011) 31:369-78. doi: 10.1007/s10875-010-9496-0

36. Lozano JM, Gonzalez R, Kindelan JM, Rouas-Freiss N, Caballos R, Dausset J, et al. Monocytes and T lymphocytes in HIV-1-positive patients express HLA-G molecule. AIDS. (2002) 16:347-51. doi: 10.1097/00002030-200202150-00005

37. Lazana I, Zoudiari A, Kokkinou D, Themeli M, Liga M, Papadaki H, et al. Identification of a novel HLA-G+ regulatory population in blood: expansion after allogeneic transplantation and de novo HLA-G expression at graftversus-host disease sites. Haematologica. (2012) 97:1338-47. doi: 10.3324/ haematol.2011.055871

38. Mitsdoerffer M, Schreiner B, Kieseier BC, Neuhaus O, Dichgans J, Hartung HP, et al. Monocyte-derived HLA-G acts as a strong inhibitor of autologous $\mathrm{CD} 4 \mathrm{~T}$ cell activation and is upregulated by interferon-beta in vitro and in vivo: rationale for the therapy of multiple sclerosis. J Neuroimmunol. (2005) 159:155-64. doi: 10.1016/j.jneuroim.2004.09.016

39. Nunez SY, Ziblat A, Secchiari F, Torres NI, Sierra JM, Raffo Iraolagoitia $\mathrm{XL}$, et al. Human M2 macrophages limit NK cell effector functions through secretion of TGF-beta and engagement of CD85j. J Immunol. (2018) 200:100815. doi: $10.4049 /$ jimmunol.1700737

40. Abediankenari S, Ghasemi M, Kim YJ. Human leukocyte antigen-G expression on dendritic cells induced by transforming growth factor-beta1 and CD4+ T cells proliferation. Iran Biomed J. (2011) 15:1-5.

41. Amodio G, Mugione A, Sanchez AM, Vigano P, Candiani M, Somigliana E, et al. HLA-G expressing DC-10 and CD4(+) T cells accumulate in human decidua during pregnancy. Hum Immunol. (2013) 74:406-11. doi: 10.1016/ j.humimm.2012.11.031

42. Comi M, Avancini D, Santoni de Sio F, Villa M, Uyeda MJ, Floris M, et al. Coexpression of CD163 and CD141 identifies human circulating IL10-producing dendritic cells (DC-10). Cell Mol Immunol. (2020) 17:95-107. doi: 10.1038/s41423-019-0218-0

43. Amodio G, Comi M, Tomasoni D, Gianolini ME, Rizzo R, LeMaoult J, et al. HLA-G expression levels influence the tolerogenic activity of human DC-10. Haematologica. (2015) 100:548-57. doi: 10.3324/haematol.2014.113803

44. Amodio G, Sales de Albuquerque R, Gregori S. New insights into HLA-G mediated tolerance. Tissue Antigens. (2014) 84:255-63. doi: 10.1111/tan.12427

45. Vigano S, Negron JJ, Tse S, Chowdhury FZ, Lichterfeld M, Yu XG. HLA-G+ HIV-1-specific CD8+ T cells are associated with HIV-1 immune control. AIDS. (2017) 31:207-12. doi: 10.1097/QAD.0000000000001326

46. Lozano JM, Gonzalez R, Luque J, Frias M, Rivero A, Pena J. CD8(+)HLA-G(+) regulatory T cells are expanded in HIV-1-infected patients. Viral Immunol. (2009) 22:463-5. doi: 10.1089/vim.2009.0041

47. Li C, Toth I, Schulze Zur Wiesch J, Pereyra F, Rychert J, Rosenberg ES, et al. Functional characterization of HLA-G(+) regulatory T cells in HIV-1 infection. PLoS Pathog. (2013) 9:e1003140. doi: 10.1371/journal.ppat.1003140 
48. Vianna P, Mondadori AG, Bauer ME, Dornfeld D, Chies JA. HLA-G and $\mathrm{CD} 8+$ regulatory $\mathrm{T}$ cells in the inflammatory environment of pre-eclampsia. Reproduction. (2016) 152:741-51. doi: 10.1530/REP-15-0608

49. Hsu P, Santner-Nanan B, Joung S, Peek MJ, Nanan R. Expansion of CD4(+) HLA-G(+) T Cell in human pregnancy is impaired in pre-eclampsia. Am J Reprod Immunol. (2014) 71:217-28. doi: 10.1111/aji.12195

50. Wang C, Chen J, Zhang Q, Li W, Zhang S, Xu Y, et al. Elimination of CD4(low)HLA-G(+) T cells overcomes castration-resistance in prostate cancer therapy. Cell Res. (2018) 28:1103-17. doi: 10.1038/s41422-018-0089-4

51. Ostapchuk EO, Perfi L'eva YV, Talaeva S, Omarbaeva NA, Belyaev NN. Content of HLA-G(+) T cells in the peripheral blood from healthy women and breast cancer patients. Bull Exp Biol Med. (2015) 159:649-51. doi: 10. 1007/s10517-015-3038-y

52. Ostapchuk YO, Cetin EA, Perfilyeva YV, Yilmaz A, Skiba YA, Chirkin AP, et al. Peripheral blood NK cells expressing HLA-G, IL-10 and TGF-beta in healthy donors and breast cancer patients. Cell Immunol. (2015) 298:37-46. doi: 10.1016/j.cellimm.2015.09.002

53. Lin A, Yan WH. Human leukocyte antigen-G (HLA-G) expression in cancers: roles in immune evasion, metastasis and target for therapy. Mol Med. (2015) 21:782-91. doi: 10.2119/molmed.2015.00083

54. Lin A, Yan WH. Heterogeneity of HLA-G expression in cancers: facing the challenges. Front Immunol. (2018) 9:2164. doi: 10.3389/fimmu.2018.02164

55. Brown R, Kabani K, Favaloro J, Yang S, Ho PJ, Gibson J, et al. CD86+ or HLA-G+ can be transferred via trogocytosis from myeloma cells to T cells and are associated with poor prognosis. Blood. (2012) 120:2055-63. doi: 10.1182/blood-2012-03-416792

56. Locafaro G, Amodio G, Tomasoni D, Tresoldi C, Ciceri F, Gregori S. HLA-G expression on blasts and tolerogenic cells in patients affected by acute myeloid leukemia. J Immunol Res. (2014) 2014:636292. doi: 10.1155/2014/636292

57. Bortolotti D, LeMaoult J, Trapella C, Di Luca D, Carosella ED, Rizzo R. Pseudomonas aeruginosa quorum sensing molecule N-(3-Oxododecanoyl)-Lhomoserine-lactone induces HLA-G expression in human immune cells. Infect Immun. (2015) 83:3918-25. doi: 10.1128/IAI.00803-15

58. Lu N, Zhang Y, Zou X, Yang X, Tian J, Zhen J, et al. HLA-G on peripheral blood CD4(+) T lymphocytes: a potential predictor for acute renal rejection. Transpl Int. (2011) 24:1103-11. doi: 10.1111/j.1432-2277.2011.01314.X

59. Le Rond S, Le Maoult J, Creput C, Menier C, Deschamps M, Le Friec G, et al. Alloreactive CD4+ and CD8+ T cells express the immunotolerant HLA-G molecule in mixed lymphocyte reactions: in vivo implications in transplanted patients. Eur J Immunol. (2004) 34:649-60. doi: 10.1002/eji.200324266

60. Contini P, Puppo F, Canonica GW, Murdaca G, Ciprandi G. Allergen-driven HLA-G expression and secretion in peripheral blood mononuclear cells from allergic rhinitis patients. Hum Immunol. (2016) 77:1172-8. doi: 10.1016/j. humimm.2016.08.005

61. Murdaca G, Contini P, Negrini S, Ciprandi G, Puppo F. Immunoregulatory role of HLA-G in allergic diseases. J Immunol Res. (2016) 2016:6865758. doi: $10.1155 / 2016 / 6865758$

62. Castellaneta A, Mazariegos GV, Nayyar N, Zeevi A, Thomson AW. HLA-G level on monocytoid dendritic cells correlates with regulatory T-cell Foxp3 expression in liver transplant tolerance. Transplantation. (2011) 91:1132-40.

63. da Silva EZ, Jamur MC, Oliver C. Mast cell function: a new vision of an old cell. J Histochem Cytochem. (2014) 62:698-738. doi: 10.1369/0022155414545334

64. Jarido V, Kennedy L, Hargrove L, Demieville J, Thomson J, Stephenson K, et al. The emerging role of mast cells in liver disease. Am J Physiol Gastrointest Liver Physiol. (2017) 313:G89-101.

65. Franceschini B, Ceva-Grimaldi G, Russo C, Dioguardi N, Grizzi F. The complex functions of mast cells in chronic human liver diseases. Dig Dis Sci. (2006) 51:2248-56.

66. Amiot L, Vu N, Samson M. Biology of the immunomodulatory molecule HLA-G in human liver diseases. J Hepatol. (2015) 62:1430-7.

67. Amiot L, Vu N, Rauch M, L'Helgoualc'h A, Chalmel F, Gascan H, et al. Expression of HLA-G by mast cells is associated with hepatitis $\mathrm{C}$ virus-induced liver fibrosis. J Hepatol. (2014) 60:245-52.

68. Ouyang Y, Nakao A, Han D, Zhang L. Transforming growth factor-betal promotes nasal mucosal mast cell chemotaxis in murine experimental allergic rhinitis. ORL J Otorhinolaryngol Relat Spec. (2012) 74:117-23.

69. Gruber BL, Marchese MJ, Kew RR. Transforming growth factor-beta 1 mediates mast cell chemotaxis. J Immunol. (1994) 152:5860-7.
70. Gruber BL, Kew RR, Jelaska A, Marchese MJ, Garlick J, Ren S, et al. Human mast cells activate fibroblasts: tryptase is a fibrogenic factor stimulating collagen messenger ribonucleic acid synthesis and fibroblast chemotaxis. $J$ Immunol. (1997) 158:2310-7.

71. Flynn JK, Dore GJ, Hellard M, Yeung B, Rawlinson WD, White PA, et al. Early IL-10 predominant responses are associated with progression to chronic hepatitis C virus infection in injecting drug users. J Viral Hepat. (2011) 18:549-61.

72. Lau DT, Fish PM, Sinha M, Owen DM, Lemon SM, Gale M Jr. Interferon regulatory factor-3 activation, hepatic interferon-stimulated gene expression, and immune cell infiltration in hepatitis C virus patients. Hepatology. (2008) 47:799-809. doi: 10.1002/hep.22076

73. Gomes RG, Brito CAA, Martinelli VF, Santos RND, Gomes F, Peixoto CA, et al. HLA-G is expressed in intestinal samples of ulcerative colitis and Crohn's disease patients and HLA-G5 expression is differentially correlated with TNF and IL-10 cytokine expression. Hum Immunol. (2018) 79:477-84.

74. Yoon BS, Kim YT, Kim JW, Kim SH, Kim JH, Kim SW. Expression of human leukocyte antigen-G and its correlation with interleukin-10 expression in cervical carcinoma. Int J Gynaecol Obstet. (2007) 98:48-53. doi: 10.1016/j.ijgo. 2007.03.041

75. Urosevic M, Dummer R. HLA-G and IL-10 expression in human cancerdifferent stories with the same message. Semin Cancer Biol. (2003) 13:337-42.

76. Ugurel S, Reinhold U, Tilgen W. HLA-G in melanoma: a new strategy to escape from immunosurveillance? Onkologie. (2002) 25:129-34.

77. Ugurel S, Rebmann V, Ferrone S, Tilgen W, Grosse-Wilde H, Reinhold U. Soluble human leukocyte antigen-G serum level is elevated in melanoma patients and is further increased by interferon-alpha immunotherapy. Cancer. (2001) 92:369-76.

78. Chu W, Yang Y, Geraghty DE, Hunt JS. Interferons enhance HLA-G mRNA and protein in transfected mouse fibroblasts. J Reprod Immunol. (1999) 42:115. doi: 10.1016/s0165-0378(98)00077-1

79. Dendrou CA, Fugger L, Friese MA. Immunopathology of multiple sclerosis. Nat Rev Immunol. (2015) 15:545-58.

80. Rodi M, Dimisianos N, de Lastic AL, Sakellaraki P, Deraos G, Matsoukas J, et al. Regulatory cell populations in relapsing-remitting multiple sclerosis (RRMS) patients: effect of disease activity and treatment regimens. Int J Mol Sci. (2016) 17:1398. doi: 10.3390/ijms17091398

81. Sampson JH, Gunn MD, Fecci PE, Ashley DM. Brain immunology and immunotherapy in brain tumours. Nat Rev Cancer. (2020) 20:12-25. doi: 10.1038/s41568-019-0224-7

82. Castro Dias M, Mapunda JA, Vladymyrov M, Engelhardt B. Structure and junctional complexes of endothelial, epithelial and glial brain barriers. Int $\mathrm{J}$ Mol Sci. (2019) 20:5372. doi: 10.3390/ijms20215372

83. Wiendl H, Feger U, Mittelbronn M, Jack C, Schreiner B, Stadelmann C, et al. Expression of the immune-tolerogenic major histocompatibility molecule HLA-G in multiple sclerosis: implications for CNS immunity. Brain. (2005) 128(Pt 11):2689-704.

84. Tsokos GC. Systemic lupus erythematosus. N Engl J Med. (2011) 365:2110-21.

85. Dorner T, Furie R. Novel paradigms in systemic lupus erythematosus. Lancet. (2019) 393:2344-58.

86. Bruschi M, Bonanni A, Petretto A, Vaglio A, Pratesi F, Santucci L, et al. Neutrophil extracellular traps profiles in patients with incident systemic lupus erythematosus and lupus nephritis. J Rheumatol. (2020) 47:377-86.

87. Tsokos GC. Autoimmunity and organ damage in systemic lupus erythematosus. Nat Immunol. (2020) 21:605-14.

88. Ohl K, Tenbrock K. Regulatory T cells in systemic lupus erythematosus. Eur J Immunol. (2015) 45:344-55.

89. Li W, Deng C, Yang H, Wang G. The regulatory T cell in active systemic lupus erythematosus patients: a systemic review and meta-analysis. Front Immunol. (2019) 10:159. doi: 10.3389/fimmu.2019.00159

90. Rosado S, Perez-Chacon G, Mellor-Pita S, Sanchez-Vegazo I, Bellas-Menendez C, Citores MJ, et al. Expression of human leukocyte antigen-G in systemic lupus erythematosus. Hum Immunol. (2008) 69:9-15.

91. Wu Y, Cai B, Feng W, Yang B, Huang Z, Zuo C, et al. Double positive CD4+CD8+ T cells: key suppressive role in the production of autoantibodies in systemic lupus erythematosus. Indian J Med Res. (2014) 140:513-9.

92. Gabrielli A, Avvedimento EV, Krieg T. Scleroderma. N Engl J Med. (2009) 360:1989-2003. 
93. Gemignani L, Savarino V, Ghio M, Parodi A, Zentilin P, de Bortoli N, et al. Lactulose breath test to assess oro-cecal transit delay and estimate esophageal dysmotility in scleroderma patients. Semin Arthritis Rheum. (2013) 42:522-9.

94. Fenoglio D, Bernuzzi F, Battaglia F, Parodi A, Kalli F, Negrini S, et al. Th17 and regulatory $\mathrm{T}$ lymphocytes in primary biliary cirrhosis and systemic sclerosis as models of autoimmune fibrotic diseases. Autoimmun Rev. (2012) 12:300-4.

95. Fenoglio D, Battaglia F, Parodi A, Stringara S, Negrini S, Panico N, et al. Alteration of Th17 and Treg cell subpopulations co-exist in patients affected with systemic sclerosis. Clin Immunol. (2011) 139:249-57.

96. Papp G, Horvath IF, Barath S, Gyimesi E, Sipka S, Szodoray P, et al. Altered T-cell and regulatory cell repertoire in patients with diffuse cutaneous systemic sclerosis. Scand J Rheumatol. (2011) 40:205-10.

97. Tardito S, Negrini S, Conteduca G, Ferrera F, Parodi A, Battaglia F, et al. Indoleamine 2,3 dioxygenase gene polymorphisms correlate with CD8+ Treg impairment in systemic sclerosis. Hum Immunol. (2013) 74:166-9.

98. Parel Y, Aurrand-Lions M, Scheja A, Dayer JM, Roosnek E, Chizzolini C. Presence of CD4+CD8+ double-positive T cells with very high interleukin4 production potential in lesional skin of patients with systemic sclerosis. Arthritis Rheum. (2007) 56:3459-67.

99. McIntire RH, Morales PJ, Petroff MG, Colonna M, Hunt JS. Recombinant HLA-G5 and -G6 drive U937 myelomonocytic cell production of TGF-beta1. J Leukoc Biol. (2004) 76:1220-8.

100. Greaves MW, Weinstein GD. Treatment of psoriasis. N Engl J Med. (1995) 332:581-8.

101. Espinoza LR, Cuellar ML, Silveira LH. Psoriatic arthritis. Curr Opin Rheumatol. (1992) 4:470-8.
102. Lowes MA, Bowcock AM, Krueger JG. Pathogenesis and therapy of psoriasis. Nature. (2007) 445:866-73.

103. Cardili RN, Alves TG, Freitas JC, Soares CP, Mendes-Junior CT, Soares EG, et al. Expression of human leucocyte antigen-G primarily targets affected skin of patients with psoriasis. Br J Dermatol. (2010) 163:769-75.

104. Aractingi S, Briand N, Le Danff C, Viguier M, Bachelez H, Michel L, et al. HLA-G and NK receptor are expressed in psoriatic skin: a possible pathway for regulating infiltrating T cells? Am J Pathol. (2001) 159:71-7.

105. Kupper TS, Fuhlbrigge RC. Immune surveillance in the skin: mechanisms and clinical consequences. Nat Rev Immunol. (2004) 4:211-22.

106. Khosrotehrani K, Le Danff C, Reynaud-Mendel B, Dubertret L, Carosella ED, Aractingi S. HLA-G expression in atopic dermatitis. J Invest Dermatol. (2001) $117: 750-2$.

Conflict of Interest: The authors declare that the research was conducted in the absence of any commercial or financial relationships that could be construed as a potential conflict of interest.

Copyright (c) 2020 Contini, Murdaca, Puppo and Negrini. This is an open-access article distributed under the terms of the Creative Commons Attribution License (CC BY). The use, distribution or reproduction in other forums is permitted, provided the original author(s) and the copyright owner(s) are credited and that the original publication in this journal is cited, in accordance with accepted academic practice. No use, distribution or reproduction is permitted which does not comply with these terms. 